\title{
Arquivo e os tribunais da história: memória e desejo na transmissão da cultura
}

Cristiane Rose Duarte*

Paula Uglione**

\section{Resumo}

O presente artigo apresenta uma reflexão sobre a noção de arquivo no pensamento contemporâneo, através de duas perspectivas teóricas, quais sejam, a teoria psicanalítica e a abordagem histórica de Pierre Nora. Enquanto a teoria psicanalítica e seus desdobramentos apontam para o caráter desejante de toda montagem de arquivo na cultura, Pierre Nora vislumbra no compromisso de arquivo da sociedade atual um processo de historicização do mundo, o que significa o fim de uma memória-viva na cultura. Sob a óptica psicanalítica, pode-se entender que se há diferenças entre memória e história, uma delas está nas marcas que o desejo e a fantasia deixam em qualquer arquivo. Marcas, estas, impensáveis numa história enquanto reconstituição do passado como ele aconteceu. Se a história é uma prótese, como lamenta NORA (1997) é justamente porque, acima de tudo, a memória é invenção.

Palavras-chave: Arquivo. Memória. História.

Archives and forum of history: memory and desire in the transmission of culture

\section{Abstract}

This article presents a thought on the notion of archive in the contemporary thinking, through two theoretical perspectives, that is, the psycoanalytical theory and Pierre Nora's historical approach. While the psycoanalytical theory and its unfolding theories lead to the desiring character of the whole assembly of archive in the culture, Pierre Nora sees in the archive commitment of the present society a process of historization of the world, which means the end of a live memory in the culture. Under the psychoanalytical view, it can be understood that if there are differences between memory and history, one of them is in the marks that desire and fantasy 
leave in any archive. Unthinkable marks in a history considering the reconstitution of the past as it happened. If history is a protesis, as NORA (1997) regrets it, it is just because, above all, memory is an invention.

Key-words: Archive. Memory. History.

Assim como a racionalidade medieval acreditou na escritura como chave para "congelar a memória", a modernidade foi aquela que começou a desconfiar disto, e muitas águas tiveram que rolar até que esta desconfiança se transformasse no reconhecimento de que o efeito do arquivamento pode não ser, necessariamente o de "conservação" da memória, mas pode ser, pelo contrário, o de sua (da memória) substituição.

E, com esta desconfiança, um "desafeto", por parte da racionalidade contemporânea, incluindo-se a racionalidade arquitetônica e urbanística, surge com relação ao arquivo como dispositivo da memória: a idéia de arquivo passa a ser, de maneira ampla, vinculada, não de modo homogêneo, evidentemente, a uma nãovontade de memória na sociedade.

O presente artigo situa-se neste contexto: refletir sobre o estatuto do arquivo na racionalidade contemporânea. Para tanto, tomou e, de certa forma, confrontou, ideias de Sigmund Freud e a teoria psicanalítica, e a abordagem histórica de Pierre Nora.

\section{Arquivo, memória e desejo}

A inserção da psicanálise no pensamento ocidental é inegável, mesmo que através de "portas de entrada" e com relevâncias bastante diferenciadas. O legado psicanalítico à cultura deve-se, basicamente, aos textos de Sigmund Freud, lidos e interpretados nos mais diversos campos do pensamento contemporâneo, mesmo que com muitas oscilações dadas por realidades históricas, religiosas, políticas etc.

$\mathrm{Na}$ arquitetura e no urbanismo, segundo Nesbitt (2006), são nítidos os rebatimentos da psicanálise, especialmente no campo da teoria e da crítica, através de conceitos 
específicos como o de inconsciente, o de estranho, entre outros que chegam à arquitetura principalmente a partir da segunda metade do século passado.

Como toda obra complexa, extensa, não-linear, "recortada", como é a obra freudiana, alguns textos adquirem uma saliência maior enquanto outros "caem no esquecimento" ou se mostram menos atrativos.

Em 1895, Freud escreve um texto chamado Projeto de uma Psicologia Científica. Neste texto, num momento ainda iniciante de sua teorização, Freud propõe um modelo de psiquismo pensado como uma "máquina de escrever". Máquina, ou aparelho psíquico, como foi denominando por Freud, que iria, em passos sucessivos e complementares, capturando, organizando e disponibilizando elementos para serem o repertório a partir do qual as experiências perceptivas, comportamentais, cognitivas e afetivas de cada pessoa encontrariam um suporte. Máquina de escritura que dotaria a memória humana de uma extraordinária capacidade de "montar", movida por mecanismos psicológicos extremamente complexos, "verdades" a partir das quais a vida adquire significado e realidade. O psiquismo seria um arquivo de memória, e é deste arquivo e de sua maneira de arquivamento que o homem relaciona-se consigo mesmo e com o mundo que o cerca.

Modelo "engenhosamente" interessante, segundo Derrida (2005), do ponto de vista de uma revolução no estatuto da memória e de uma provocação nos paradigmas filosóficos da verdade, do tempo e da história, que ele estaria colocando em cena.

Este texto, curiosamente, é um dos menos lidos e menos conhecidos dentre os textos freudianos, na cultura de modo geral (BIRMAN, 2008). Por algum motivo coincidência? - ele é pouco atrativo para o pensamento contemporâneo e, ao que tudo indica, "esquecido" pela arquitetura e pelo urbanismo em suas reflexões sobre a memória e o patrimônio cultural na cidade moderna.

Segundo o mesmo Freud (1900), todo esquecimento insistente é sinal de encobrimento e, portanto, é um convite a interrogações. O que este modelo de psiquismo, de memória, de sujeito, de história e de verdade poderiam estar dizendo 
ao pensamento contemporâneo para que ele tenha "conquistado" a importante (e necessária) posição do "negligenciado" e do "esquecido" na cultura?

Um outro olhar sobre a noção de arquivo. Esta pode ter sido uma das maiores contribuições do pensamento freudiano para a cultura. Noção, esta, que, para Deleuze (2006), provoca uma guinada no discurso da história, antes de mais nada por inserir a dimensão do inconsciente e o consequente remanejamento de uma posição positivista do tempo (o tempo como cronologia), mas também por inserir a ideia de trauma como um acontecimento (comum na vida psíquica do sujeito que é caracterizada por forças oponentes) que provoca descontinuidades, diferenças no campo do mesmo.

Freud (1913), destaca a noção de herança e de transmissão na história, rompendo, da mesma forma que outros pensadores - inclusive arquitetos como os neoracionalistas, de maneira mais explícita - com qualquer perspectiva revivalista: não há resgate do passado a ser feito, mas transformação do presente a partir das forças que vêm do passado e das promessas que vêm do futuro. Só existe herança se houver promessa; os traços que vêm do passado, os arquivos, nas palavras de Derrida (2005), são sempre classificados, interpretados por alguém, não há arquivo sem futuro, ele (o arquivo, os traços) não é uma peça morta do passado. Só há arquivo (seleção, classificação dos traços) se houver um projeto de futuro (alguém que selecionou, classificou). O arquivo é sempre construído por alguém (o historiador, o pesquisador em história, o restaurador, o arquiteto etc.). O arquivo é um instrumento de poder, há uma dimensão ética e política sempre implicada na classificação e seleção dos traços.

É a dimensão desejante no movimento da história. É por existir uma promessa (um desejo de algo, portanto, de um futuro) que o passado relampeja no presente. A história é espectral, dirá Derrida (2005), pois é marcada (invariavelmente) pela fantasia, pelo desejo; a história é uma ficção. A noção de uma documentação ficcional é, ao contrapor-se a uma documentação positivada, a grande contribuição das teorias freudianas ao discurso da história (DERRIDA, 2005). Se as inscrições psíquicas da memória (os traços) são atravessadas por fantasmas, os fatos que compõe uma história, individual ou coletiva, aconteceram ou são uma ficção do seu 
intérprete? Não tem como saber, ensina a teoria freudiana; a história aproxima-se a um imaginário literário.

Neste sentido, a relação entre memória e identidade parece modificar-se, ao menos em relação às perspectivas que atrelam de forma direta uma a outra, pois a memória, assim colocada, no campo da diferença, naquilo que se produz a partir de um rompimento com a linha contínua das coisas, não traria identidade, mas pelo contrário, traria o rompimento da identidade. A memória enquanto repetição diferencial, é simulacro, é o duplo, o estranho, o irreconhecível, ou seja, ela é a dissolução da identidade, ela provoca uma certa implosão do eu. O simulacro é uma máquina dionisíaca (DELEUZE, 2006), ele produz disfarces sucessivos, funda mundos diferenciais - e, portanto, artísticos, ficcionais.

A dimensão ficcional do psiquismo e da memória é um elemento chave na teorização freudiana.

Em sua primeira teorização sobre o sintoma, Freud (1893, p. 43) é categórico: "[...] os histéricos sofrem principalmente de reminiscências"; a causa da histeria seria a vivência real, concreta, de uma situação traumática à qual o sujeito não quer recordar, sofrendo, por isto, de lembranças (reminiscências) que não quer ter. (1). Já numa segunda teorização, na qual revê sua "teoria da sedução" (FREUD, 1896), propõe que o psiquismo está marcado por lembranças das quais o sujeito sofre, contudo, estas lembranças não são de algo que realmente aconteceu, mas de algo fantasiado; a "cena de sedução" que provoca os sintomas na histérica não aconteceram, mas foram fantasiadas., mantendo, entretanto, a capacidade de provocar um trauma.

O psiquismo é marcado por desejos e fantasmas; são as fantasias que inscrevem os traços de memória. As inscrições psíquicas, a memória, é produto das fantasias e não da realidade. (2).

Neste modelo freudiano de funcionamento do aparelho psíquico, a percepção possuiria a função de atualização, de contato e de "captação" da realidade (primeiro momento, e que é uma função da consciência), enquanto a memória possuiria a 
função de registro dos traços no psiquismo, (segundo momento que, por sua vez, é uma função do inconsciente) que serão organizados (terceiro momento, ainda pelo inconsciente) por continuidade e semelhança, representados psiquicamente (quarto momento, mas já realizado pelo pré-consciente) e finalmente levados à consciência (quinto momento). No primeiro momento, a captação é feita, mas nada é ainda inscrito no aparelho, para deixá-lo livre a novas recepções. É importante ressaltar, também, que a fantasia já participa da filtragem daquilo que passa do primeiro momento ao segundo momento, ou seja, o traço (mnemônico) já tem as marcas da fantasia, ponto importante de apoio à ideia da memória como ficção.

As ideias freudianas acerca do aparelho psíquico, e mais precisamente suas teorias sobre o sintoma, sempre tiveram alguma relação de inspiração com o modelo da história; em todas as suas teorias, o psiquismo foi pensado como um "arquivo". As inscrições psíquicas são arquivos, para a teoria freudiana. O psiquismo é memória; e a história construída por este arquivo, o arranjo das marcas que se inscreveram (memória) no psiquismo, "monta" o sintoma. Contudo, especialmente a partir da idéias de compulsão à repetição (FREUD, 1920), este arquivo é sempre concebido como "esburacado" - e esta certamente é uma outra importante contribuição das idéias freudianas para o discurso da história, na medida em que esta concepção de arquivo esburacado é, em última instância, uma crítica ao modelo positivista de arquivo (BIRMAN, 2008).

O arquivo é esburacado porque: 1) nem tudo o que aparece (está aparente) está registrado "documentalmente", pois a repressão pode ter impedido o registro de algumas percepções e sensações no psiquismo (e aquilo que insiste em retornar como algo "de fora" do sujeito, por exemplo, um sintoma que ele não "compreende" - um medo desproporcional e incontrolável frente a algumas situações etc. - é aquilo que, pelo trabalho da repressão, não foi inscrito no psiquismo); 2) algumas inscrições, para que a memória continue funcionando (para que haja espaço para a inscrição de novos traços mnemônicos) são "apagadas" do psiquismo.

O arquivo não é um documento visível - perspectiva positivista de arquivo - pois nesta "máquina de escrita", nesta "máquina arquivista" que é o psiquismo, há um mecanismo de apagamento (DERRIDA, 2005). O esquecimento é a condição da 
memória - pode-se concluir da teoria freudiana - e o que foi apagado "documentalmente" retorna como repetição, como sintoma (ou como ato falho, sonho, lapso ou chiste). Mas isto que foi apagado poderá ser "decifrado", assim como no mecanismo de deciframento do sonho (FREUD, 1900). A repetição é uma tentativa de transformar um trauma em símbolo, é uma tentativa de inscrever (e isto seria a memória) esta experiência (traumática) no psiquismo; criar um registro para aquilo que, até então, não tinha marcas.

Mais do que rememorar, transformar o que não tem marcas no psiquismo (o que está apagado) em símbolos será a proposta, por exemplo, de uma intervenção psicanalítica ou de qualquer outra proposta de intervenção "de cura", de "salvamento", de "recuperação" no campo da memória (FREUD, 1914). A memória não é um arquivo com registros a serem recuperados, ela é o exercício do registro, ela é a construção do arquivo. A memória, novamente, e sob outro ângulo teórico, é este duplo, que foi (re)criado no lugar do que não tinha ainda sido inscrito no psiquismo, do que não tinha se inserido na cadeia significante do sujeito (LACAN, 1966).

Sob esta óptica, o arquivo não é um dispositivo de restituição de um passado como ele aconteceu, até por que não há esta distância (esse "gap") entre passado, presente e futuro; na temporalidade do desejo, da fantasia e do inconsciente, há um passado presente, um presente atual e um futuro presente. Aquilo que repete (no presente atual) é um passado (presente) que foi lançado a um futuro (que já está presente) (BIRMAN, 2008).

Toda história, seja no nível individual ou no nível coletivo, é um eterno recomeço. Frente a um trauma (por exemplo, à destruição de uma edificação importante para a vida de um grupo de pessoas causada por demandas imobiliárias de novas construções) resta "juntar os pedaços", fazer um remanejamento do que era; este é o movimento da história na vida: recomeçar. E o psiquismo nada mais é do que esta (re)escritura que se vai fazendo frente aos acontecimentos da vida. O psiquismo é uma máquina escriturária (DERRIDA, 2005). 
Memória é escritura, é repetição diferencial daquilo que foi "rachado" pela intensidade do acontecimento. A memória não é linear, não segue um tempo sequencial, contínuo, cronológico, mas segue a densidade do instante, numa lógica temporal na qual um instante pode reverter o curso da vida. $\mathrm{Na}$ temporalidade lacaniana, o instante do ver é aquele no qual algo "mexe" com a tradição, com a identidade (LACAN, 1966).

Benjamin (1996) em sua concepção de história vê na mudança não tanto o surgimento de algo que potencialmente já existia e que aguardava o momento propício para surgir, mas a essência da própria cultura humana enquanto um conjunto sempre incompleto. Ou seja, mesmo que toda mudança em direção a um novo desenho urbano seja retratada como um exemplo inteiro da vida das pessoas numa determinada época, o autor mostra que este olhar que viu a 'inteireza' do movimento passado só foi possível por estarmos situados num ponto exterior, futuro, de onde foi possível vislumbrar aquilo que apareceu como novidade no passado. Diz ele: "A verdadeira imagem do passado perpassa, veloz. O passado só pode se deixar fixar como imagem que relampeja irreversivelmente no momento em que é reconhecido." (BENJAMIN, 1996, p. 224).

O sujeito, para Benjamin (1996), não possui no passado, assim como não possui no presente, o elemento de amarração essencial para entender suas experiências de vida no espaço urbano como um conjunto coerente e inteiro, com causas bem definidas, condições conhecidas e consequências previsíveis. A experiência humana é atravessada por uma indeterminação radical que só não causa mais insegurança porque, paradoxalmente, parece conduzir a uma solução: aguardamos ansiosamente pelo futuro desconhecido, pois ele dará sentido às nossas experiências atuais, assim como nós demos sentido às experiências dos nossos antepassados e interpretamos as mudanças que eles passaram não como momentos de insegurança radical, mas como passos necessários de um processo histórico bem definido.

\section{Arquivo e a memória-prótese}

Diferentemente, Pierre Nora (1997) entenderá que qualquer interposição desejante na história é justamente o momento no qual, frente ao fim da tradição da memória, 
ao haver uma subversão da história-memória em história-crítica os arquivos (e todo um modelo de historiografia subjacente a eles) serão apenas os instrumentos de uma memória voluntária e deliberada que em nada se iguala a uma memória viva, coletiva, englobante. E os "Lugares de Memória" nada mais serão do que formas de memória substitutas, memória-prótese de uma memória vivida.

A emergência do estudo dos Lugares de Memória se situam em dois movimentos: de um lado um movimento puramente historiográfico, o momento de um retorno reflexivo sobre si mesmo, e de outro, um movimento propriamente histórico, o fim da tradição de memória. (NORA, 1997, p. 28).

É com olhos na "aceleração" da história, provocada pela mundialização, massificação e midiatização da sociedade, e o consequente "desaparecimento" da memória que Nora (1997) cunhará tal termo (Lugar de Memória). É na crítica a uma percepção histórica "dilatada pela película efêmera da atualidade" que ele faz através de muitos estudos de caso, um elogio (ambivalente) aos Lugares de Memória. Nora (1997) chama de metamorfose contemporânea: uma memória "viva", coletiva, "englobante" é engalfinhada por uma memória voluntária e deliberada, vivida como um dever e não de forma espontânea. Uma cultura (contemporânea) obcecada pela conservação integral de todo o presente e pela preservação integral de todo o passado, dominada pelo sentimento de um esvaziamento rápido e definitivo combinado com a inquietude por uma significação exata do presente e por uma incerteza do futuro. Frente a isto, o mais modesto dos vestígios, o mais humilde dos testemunhos adquire a dignidade virtual de memorável.

Frente ao fim das "sociedades-memória", das "ideologias-memória", que, aliás, encontram-se fragilizadas como toda a conservação e a transmissão de valores (a Igreja, a Escola, a Família e o Estado), que a sociedade elege lugares onde se cristaliza e se refugia a memória que se esvai. É no seio de uma desritualização do mundo que os lugares de memória aparecem.

Museus, arquivos, cemitérios e coleções, festas, aniversários, tratados, monumentos, santuários, associações, são os testemunhos brutos de uma época, ilusões de eternidade. De onde o aspecto nostálgico desses empreendimentos de piedade, patéticos e glaciais. São rituais de uma sociedade sem rituais...diferenciações de acontecimentos numa 
sociedade que nivela por princípio...signos de reconhecimento e pertencimento de grupo numa sociedade que tende a não reconhecer senão indivíduos iguais e idênticos. (NORA, 1997, p. 29).

Lugar de Memória é um resto de memória; nele um sentimento de continuidade está residual. "Existem Lugares de Memória porque não há mais meios para a memória...se ainda habitássemos nossa memória, não haveria necessidade de consagrar os lugares." (NORA, 1997, p. 23). Memória e história, enfatiza Nora (1997), longe de serem sinônimos, opõem-se.

\begin{abstract}
A memória é vida, sempre carregada por grupos vivos e, nesse sentido, ela está em permanente evolução, aberta à dialética da lembrança e do esquecimento, inconsciente de suas deformações sucessivas, vulnerável a todos os usos e manipulações, susceptível de longas latências e de repentinas revitalizações. A história é a reconstrução sempre problemática e incompleta daquilo que não é mais. A memória é um fenômeno sempre atual, um elo vivido no eterno presente; a história, uma representação do passado. Porque é afetiva e mágica, a memória não se acomoda a detalhes que a confortam; ela se alimenta de lembranças vagas, telescópicas, globais ou flutuantes, particulares ou simbólicas, sensível a todas as transferências de cenas, censuras ou projeções. A história, porque operação intelectual e laicizante,demanda análise e discurso crítico. A memória instala a lembrança no sagrado, a história liberta, e a torna sempre prosaica. A memória emerge de um grupo que ela une, o que quer dizer, como Halbwachs o fez, que há tantas memórias quantos grupos existem; que ela é, por natureza, múltipla e desacelerada, coletiva, plural e individualizada. A história, ao contrário, pertence a todos e a ninguém, o que the dá uma vocação para o universal. A memória se enraíza no concreto, no espaço, no gesto, na imagem, no objeto. A história só se liga às continuidades temporais, às evoluções e às relações das coisas. A memória é um absoluto e a história só conhece o relativo. (NORA, 1997, p. 25).
\end{abstract}

A memória, para Nora (1997) é rechaçada e destruída pela história, entre elas há uma relação de suspeita; a história desligitima o passado vivido da memória. Uma ambição histórica não é exaltação do que realmente aconteceu, mas sua neantização. Os museus, medalhas e monumentos são o "arsenal" do qual a história precisa para fazer seu trabalho e por isto tratará de conservá-los. Uma inibição a destruir como se fosse possível "prejulgar aquilo do qual teremos vontade de lembrar". (NORA, 1997, p. 31). 
A produção indefinida de arquivos é o efeito de uma consciência nova, é a expressão mais clara do terrorismo da memória historicizada. A passagem da memória à história faz com que todos os grupos se sintam obrigados de redefinir sua identidade a partir da revitalização de sua própria história. A busca atualmente pelas genealogias familiares insere-se neste movimento. $O$ fim da história-memória tem multiplicado as memórias particulares que reclamam sua própria história; é uma conversão definitiva à psicologia individual, e aqui NORA (1997), situa o final do século 19 como o início dessa metamorfose, que tem sua eclosão no final do século 20, quando a memória será colocada no centro das identidades individuais. "Deslocamento decisivo da memória: de histórica à psicológica, do social ao individual, do transmissível ao subjetivo, da repetição à rememoração" (p.33), inaugura-se um novo regime de memória, um assunto agora acima de tudo privado.

Os Lugares de Memória vivem do sentimento de que não há memória espontânea, que é necessário criar arquivos, manter aniversários, organizar celebrações, notariar atos, porque estas operações não são naturais. (NORA, 1997, p. 29).

Para Nora (1997), o arquivo não é mais relicário de uma memória vivida, mas a secreção voluntária e organizada de uma memória perdida; ele dobra o vivido, ela atualiza o vivido numa memória-prótese. Quanto menos a memória é vivida do interior, mais ela precisa de suportes exteriores, precisa de lugares de memória.

Esta memória (prótese) chega ao sujeito do exterior e é internalizada como um constrangimento individual visto que ela não é mais uma prática social. "O dever de memória faz de cada um o historiador de si mesmo." (NORA, 1997, p. 32). Nesta nova "lei" do lembrar, cada um tem a obrigação de se recordar e de fazer da recuperação de um pertencimento o princípio e o segredo da identidade; este pertencimento o engaja de modo geral.

Se esta relação com o passado, dirá ela, se dá através das produções históricas mais significativas, isto nada tem a ver com o que se espera da memória. Não mais uma continuidade retrospectiva, mas a emergência da descontinuidade; é a memória-distância. 
Para uma história-memória, a percepção do passado é que ele na verdade não passou, tanto que num esforço de rememoração ele poderá ressurgir. Mesmo o presente vem a ser, por sua vez, um passado reconduzido, atualizado. Sem dúvida há o sentimento de que uma ruptura interveio entre o passado e o presente, que faz surgir um antes e um depois; mas isto parecerá menos uma separação vivida como uma diferença radical do que como um intervalo numa filiação a ser restabelecida.

Para Nora (1997), o que trataríamos de pagar com este compromisso de recordar é uma dívida impossível de pagar.

\section{Arquivo e os tribunais da vida}

Nora (1997) atribui à vontade de arquivo uma intenção (culpabilizada) de dar provas a algum tribunal da história.

Um arquivo não traz provas de nada, embora seja ele um testemunho de que sem dívida (não à história, mas à existência) não há humanidade que se sustente, no sentido daquilo que há de humano em cada um de nós e no sentido daquilo que há de cultura em toda história. Por que seria desmerecedor assumir nossa dívida - e portanto nossa culpa - com o mundo que nos cerca? Nosso compromisso de transmissão, afinal, não vem da nossa dívida com nossas heranças? Por que haveríamos de querer o direito à memória sem o dever de escrever a história? Este não tem sido o drama, o mal-estar do sujeito "sem gravidade", sujeito que vê enormemente simplificada a preocupação de tomar lugar no campo dos deveres, incluídos os deveres de memória (MELMAN, 2003)?

Memória "[...] é uma corrente de pensamento contínuo que nada tem de artificial" (NORA, 1997, p. 84). A memória é lúdica sim, mas não é uma distração da alma. Ela não é um passeio livre por um paraíso ingênuo e intocável pela realidade. Se há uma diferença entre memória e história não parece ser a de uma contraposição entre algo espontâneo, vivo e algo artificial, memória-prótese (estamos voltando à dicotomia verdadeiro/falso, natural/artificial platônica?); entre uma história-memória e uma história-crítica (NORA, 1997) ou entre uma memória fenomênica e história (HALBWACHS, 1997). 
Se há diferenças entre memória e história, uma delas está nas marcas que o desejo e a fantasia deixam em qualquer arquivo. Marcas, estas, impensáveis numa história enquanto reconstituição do passado como ele aconteceu. Se a história é uma prótese, como lamenta Nora (1997) é justamente porque, acima de tudo, a memória é invenção - e quanto a isto não parece que haja o que lamentar.

Os animais têm sistemas orgânicos receptores dos estímulos do meio e mecanismos de armazenagem destes estímulos, podendo-se tranquilamente admitir que eles (os animais) possuem, por isto, memória - e os comportamentalistas já demonstraram com muita propriedade as semelhanças, com relação a estas habilidades, entre seres humanos e outros animais. Mas o arquivo humano é desejante. Esta é a diferença; é um arquivo esburacado (DERRIDA, 2005), é um arquivo "montado" pelo desejo, pela fantasia. E desejo não é instinto (FREUD, 1920) e, portanto, memória não é guardiã e guia de necessidades práticas da vida.

Não há intenção significadora das coisas do mundo (MERLEAU-PONTY, 2006), mas força desejante nas intenções humanas de significação das coisas do mundo.

Afinal é porque a percepção e a memória são atravessadas pelo desejo que as histórias (humanas) são errantes, e inclusive levam a caminhos "errados", o que não acontece com os animais que, guiados por uma memória instintiva, trilham seus caminhos em linha certeira. Histórias errantes que levam a ver no passado o que não aconteceu, por exemplo, ou deixar de ver o que aconteceu (FREUD, 1896). Assim são as histórias humanas.

Eu prefiro, de longe, a expressão trabalho de memória a dever de memória, pois não vejo por que a memória seria um dever, enquanto que o trabalho de memória é uma exigência da vida. (RICOUER, 1998, p. 49).

Que seja trabalho e não dever de memória, se com isto o autor esteja salientando que não há por que tomar como fardo o que é a condição (exigência) mesma da vida: escrever histórias - o que não deixa de ser construir um presente e um futuro. Se "[...].o dever de memória faz de cada um o historiador de si mesmo" (NORA, 1997, p. 32) não é porque a memória deixou de ser natural e agora, sob o crivo 
crítico do historiador, virou (mera) história. É porque ser historiador - ou intérprete de arquivos (DERRIDA, 2005) - é o trabalho do (ser humano) vivente. Escrever histórias é compromisso da vida. E compromisso com a vida.

\section{O "arquivamento" (ou a construção de arquivos) não é uma solução para a vontade} de não lembrar que estaria presente na sociedade, mas uma possibilidade (talvez a única) de escrever histórias que respeitem a vontade (inevitável e necessária) de esquecer, dessa sociedade. Vontade, esta, inerente ao humano e não exclusividade - deixemos de ser narcisistas! - da época atual.

\section{Notas}

(1) Para Freud (1901), o esquecimento é a expressão da recusa da lembrança a funcionar. No esquecimento aconteceria uma "seleção"; na base de todo o esquecimento é possível encontrar um motivo de desprazer, ou seja, aquilo que é "selecionado" para não chegar à consciência parece sempre estar ligado de forma direta ou indireta a pensamentos ou a sentimentos que causam desprazer para a pessoa. Uma "resistência se oporia à lembrança de impressões ou experiências aflitivas, à representação de pensamentos aflitivos" (p. 152). Resistência, esta que funciona como um empenho defensivo comparável ao reflexo de fuga na presença de estímulos dolorosos. "Quando analiso os casos de esquecimento de nomes que observo em mim mesmo, quase sempre descubro que o nome retido relaciona-se com um tema que me é de grande importância pessoal e que é capaz de evocar em mim afetos intensos e quase sempre penosos" (p. 39).

(2) Esta (complexa) relação entre percepção, memória, consciência e inconsciente é apresentada na teoria freudiana através do modelo de funcionamento psíquico descrito no texto "Projeto de uma Psicologia". Neste texto, Freud (1895) elabora uma teoria considerando que o psiquismo é como um "aparelho" capaz de transmitir e de transformar energia: os neurônios, em movimentos alternados de atividade e de repouso fariam a transmissão e a transformação da energia (Q) que existe no aparelho psíquico; energia essa que foi gerada no psiquismo tanto por estímulos externos (provenientes dos sentidos da audição, da visão, do tato, do paladar) quanto por estímulos internos (provenientes da fome, da respiração, da sexualidade etc) ao organismo humano. Por um princípio de inércia, os neurônios tenderiam antes de tudo a buscar a descarga de toda a quantidade de energia (Q) que recebem, embora esses mesmos neurônios possuam uma estrutura que oferece resistência à descarga total e que Freud chamou as "barreiras de contato". Em outras palavras, os neurônios estão investidos (1) de uma quantidade de $Q$ da qual tendem a se livrar e, para isto, além de "escoar" a energia acumulada também buscariam conservar vias de passagem que possibilitariam que o sistema nervoso ficasse afastado daquelas fontes que produzem Q. Assim, além da função de descarga, o movimento dos neurônios teria a função de "fuga do estímulo". Por um lado uma tendência à descarga e por outro uma tendência a impedir a livre passagem dessa energia, e as "barreiras de contato" enquanto resistências localizadas nos pontos de contato entre os neurônios fariam este impedimento da passagem da energia. As barreiras de contato agem apenas sobre os neurônios impermeáveis, ou seja, sobre aqueles que depois de uma passagem de $Q$ (provocada sempre por uma estimulação externa ou interna) podem se modificar, ficar diferentes do que eram anteriormente, enquanto que os neurônios permeáveis deixam Q passar como se não houvesse barreira de contato, retornando 
ao mesmo estado depois de cada passagem de $Q$, não sendo modificados por ela. Os neurônios permeáveis, então, ficariam disponíveis para receber novas estimulações e, por isto, garantem ao psiquismo a realização da função perceptiva. Os neurônios impermeáveis, por sua vez, estão ocupados pela energia que por eles vai passando, formando a base mnemônica do psiquismo.

\section{Referências bibliográficas}

BENJAMIN, Walter. A obra de arte na era de sua reprodutibilidade técnica (1936). In: Obras escolhidas I. São Paulo: Editora Brasiliense, 1996.

BIRMAN, Joel. Memória, arquivo e inconsciente: da história à genealogia. Curso Livre ministrado no Pólo de Pensamento Contemporâneo. Rio de Janeiro, jul. 2008.

DELEUZE, Gilles. Diferença e repetição. São Paulo: Graal, 2006.

DERRIDA, Jacques. Mal de arquivo: uma impressão freudiana. Rio de Janeiro: Relume-Dumará, 2005.

FREUD, Sigmund. (1893-1895). Estudos sobre a histeria. Edição Standard Brasileira das Obras Psicológicas Completas de Sigmund Freud. Vol. II. Rio de Janeiro: Imago, 2006.

(1895) Projeto de uma psicologia. Edição Standard Brasileira das Obras Psicológicas Completas de Sigmund Freud. Vol. I. Rio de Janeiro: Imago, 2006.

(1896) A etiologia das neuroses. Edição Standard Brasileira das Obras Psicológicas Completas de Sigmund Freud. Vol. III. Rio de Janeiro: Imago, 2006.

(1900) A interpretação dos sonhos. Edição Standard Brasileira das Obras Psicológicas Completas de Sigmund Freud. Vol. IV. Rio de Janeiro: Imago, 2006.

(1913) Totem e Tabu. Edição Standard Brasileira das Obras Psicológicas Completas de Sigmund Freud. Vol. XIII. Rio de Janeiro: Imago, 2006.

(1914) Recordar, repetir e elaborar. Edição Standard Brasileira das Obras Psicológicas Completas de Sigmund Freud. Vol. XII. Rio de Janeiro: Imago, 2006.

(1920) Além do princípio do prazer. Edição Standard Brasileira das Obras Psicológicas Completas de Sigmund Freud. Vol. XVIII. Rio de Janeiro: Imago, 2006

HALBWACHS, Maurice. La mémoire colletive. Paris: Albin Michel, 1997.

LACAN, Jacques. O tempo lógico e a noção de certeza antecipada. In: Écrits I. Paris: Éditions du Seuil, 1966.

MELMAN, Charles. O homem sem gravidade: gozar a qualquer preço. Rio de Janeiro: Companhia de Freud, 2003. 
MERLEAU-PONTY, Maurice. Fenomenologia da percepção. São Paulo: Martins Fontes, 2006.

NESBITT, Kate. Uma nova agenda para a arquitetura: antologia teórica 1965-1995. São Paulo: Cosac Naify, 2006.

NORA, Pierre. Entre mémoire et histoire: la problématique des lieux. In: Les Lieux de Mémoires. Paris: Gallimard, 1997.

RICOEUR, Paul. Arquitetura e narratividade. Urbanisme, n. 303, p. 44-51, nov./dez 1998.

\section{Créditos}

* Arquiteta, doutora pela Université de Paris I e professora titular do Programa de Pós-Graduação em Arquitetura da Faculdade de Arquitetura e Urbanismo da Universidade Federal do Rio de Janeiro (PROARQ - FAU - UFRJ). e-mail:crsduarte@gmail.com

** Psicóloga graduada pela Pontifícia Universidade Católica do Rio Grande do Sul (PUC/RS), mestre em Psicologia pela Pontifícia Universidade Católica do Rio Grande do Sul (PUC/RS), doutora em Arquitetura pela Faculdade de Arquitetura e Urbanismo da Universidade Federal do Rio de Janeiro (FAU - UFRJ). Pósdoutoranda no Programa de Pós-Graduação em Arquitetura da Faculdade de Arquitetura e Urbanismo da Universidade Federal do Rio de Janeiro (PROARQ - FAU - UFRJ) e bolsista PAPD/FAPERJ.

e-mail: puglione@ig.com.br

artigo recebido em 02/2010

aprovado em 04/2010 